\title{
Foraging ecology of the South Australian glossy black-cockatoo (Calyptorhynchus lathami halmaturinus)
}

\author{
J. W. PEPPER, ${ }^{1 \star}$ T. D. MALE ${ }^{2}$ AND G. E. ROBERTS ${ }^{2}$ \\ ${ }^{1}$ Museum of Zoology, The University of Michigan, Ann Arbor, Michigan and ${ }^{2}$ Department of Zoology, \\ The University of Hawaii, Honolulu, Hawaii, USA
}

\begin{abstract}
The endangered South Australian glossy black-cockatoo (Calyptorhynchus lathami halmaturinus Mathews 1912) feeds almost exclusively on the seeds of the drooping sheoak (Allocasuarina verticillata), and shows marked preferences for individual trees. This field study investigated foraging ecology and tree selection through observations of foraging birds and measurements of trees and seed cones. The cockatoos spent the vast majority of their foraging time (94\%) handling seed cones, and handling behaviour was highly stereotyped. Handling time per cone was correlated primarily with cone size, while seed intake rate was correlated primarily with seed mass per cone. The cockatoos fed mostly in trees with signs of previous feeding. They tended initially to sample trees with large seeds, and to stay for long feeding bouts in trees with high ratios of seed-to-cone mass. As a result of these biases, feeding was concentrated in trees with high seed mass per cone. Preferred trees were also larger, with higher ratios of seed-to-cone mass and larger seeds containing more lipid and protein. By feeding from selected trees the cockatoos increased both their seed intake rate and the nutritional quality of the seeds ingested, thereby increasing their energy intake rate by an estimated $28 \%$. They did not discriminate against trees that had re-grown from basal shoots after fires. Insect larvae were present in some seed cones but the cockatoos did not appear to actively seek them. Males foraged $19 \%$ more efficiently than females, resulting in greater daily food intake. The characteristics of individual $A$. verticillata trees that determined the cockatoos' feeding rates were also correlated with their distribution on a regional scale. This suggests that the distribution of this endangered cockatoo depends not only on the presence of food trees, but also on their regionally varying feeding profitability.
\end{abstract}

Key words: Allocasuarina verticillata, conservation, diet, distribution, feeding profitability, feeding rate, Kangaroo Island, seeds.

\section{INTRODUCTION}

The glossy black-cockatoo Calyptorhynchus lathami is unique among Australian parrots in its degree of feeding specialisation, foraging almost exclusively on the seeds of Allocasuarina trees throughout its range (Cleland \& Sims 1968; Anon. 1976; Joseph 1982; Blakers et al. 1984; Baxter 1989; Clout 1989; Forshaw 1989). This specialisation makes it possible to measure feeding rates and nutritional intake. It also makes the species vulnerable to habitat destruction, which is of particular concern for the small and isolated South Australian subspecies, C. l. halmaturinus (Garnett \& Gross 1992). Although formerly present on the mainland, C. l. halmaturinus is now restricted to Kangaroo Island, South Australia, where its numbers are estimated at $<200$ individuals (Joseph 1982; Pepper 1996, 1997).

The foraging ecology of only one of the three sub-

${ }^{\star}$ Correspondence address: J. W. Pepper, Santa Fe Institute, 1399 Hyde Park Road, Santa Fe, NM 87501, USA (Email: jpepper@santafe.edu).

Accepted for publication April 1999. species has been studied previously. C. l. lathami in New South Wales feeds exclusively on Allocasuarina littoralis, and shows strong preferences for individual trees, preferring those with high ratios of seed-to-cone mass (Clout 1989). Clout suggested that these cockatoos might select those individual trees that maximise their food intake rate. On Kangaroo Island, C. l. halmaturinus feeds almost exclusively on the drooping sheoak Allocasuarina verticillata (Joseph 1982; Pepper 1993, 1996, 1997). Female drooping sheoaks produce woody barrel-shaped seed cones $20-50 \mathrm{~mm}$ long that contain many small, dry, one-winged fruits (samaras), each with a single seed (Wilson \& Johnson 1989). A samara technically consists of a seed and its surrounding husk but we refer to them hereafter simply as seeds. Seed cones are retained on the tree and do not usually release their seeds for more than a year, so that seed-bearing cones are present year round. Seed cones change colour slowly, so that annual cohorts can be distinguished.

The C. l. halmaturinus population does not use all the foraging habitat available on Kangaroo Island but feeds most heavily in those areas where drooping sheoaks have the greatest total seed mass per cone (Pepper 1997). Together with previous findings on 
the foraging ecology of the eastern subspecies (Clout 1989), this suggests the following hypotheses concerning the Kangaroo Island subspecies: (i) that $C . l$. halmaturinus also selects the most profitable trees to forage in; (ii) that the foraging profitability of $A$. verticillata trees is highly correlated with their seed mass per cone; and (iii) that the distribution of cockatoos across the island is influenced by the same foraging preferences demonstrated among individual trees. The goals of this study were to describe the feeding behaviour of C. l. halmaturinus and the characteristics of their food trees, and to test these three hypotheses.

\section{METHODS}

We collected data between 7 April and 24 May 1993 (during the nesting season) in approximately 4 ha of Lathami Conservation Park on the north coast of Kangaroo Island, South Australia. Allocasuarina verticillata grew mainly in pure stands of varying ages. Some stands included multi-stemmed trees typical of basal reshooting after the above-ground parts were killed by fire (Pepper 1997).

We observed 17 individually identifiable cockatoos, including eight paired females, seven paired males and two unpaired males. Only one of these pairs nested during the study. All subjects had adult plumage except one paired female with no yellow markings on the head, which is characteristic of subadults. Individual females were identified by distinctive plumage markings on the head and tail. Males were identified either by plumage markings (four males), missing flight feathers (two males), or consistent close association with a known female (three males). We also observed several unpaired males that were not identified individually. Our methods largely followed those of Clout (1989).

\section{Observing foraging birds}

In order to sample as evenly as possible from different individuals, we used a priority list to search for birds that had been observed less frequently. When we encountered an individual from this list, we began an observation session that included the initial subject and its mate if paired, any birds that shared a foraging tree with the initial pair, and their mates. One individual feeding in one tree was considered a foraging bout, so an observation session included at least one bout for each foraging cockatoo present, or more if they changed trees during the session. We recorded the time when a subject first touched and finally dropped each cone, whether the cone was partially or completely shredded, and whether the cockatoo paused for more than $5 \mathrm{~s}$ while handling the cone. For each bout we recorded at least 10 complete cone handling times when possible. We also noted the individual and tree involved, and whether the subject left the tree to forage nearby.

A session ended either when all the foraging birds left the visible area, or when at least 10 complete handling times had been recorded from each current bout and the cockatoos had been allowed to forage for at least $1 \mathrm{~h}$. At the end of the session we noted how many freshly chewed cone ends were beneath each tree, as well as the number that were only partly eaten, that showed evidence of infestation by parasitic insect larvae, and that were chewed from the distal end (leaving the attached stem intact).

During 61 observation sessions the cockatoos ate 1382 cones in 128 bouts in 73 trees. We defined foraging time to exclude inactive periods of $>2 \mathrm{~min}$ and gaps in feeding of $>5 \mathrm{~min}$. Foraging was divided into handling time, while the cockatoos were in contact with a seed cone, and intervening search time. For analyses based on handling times, we included only cones that were chewed completely with no pauses longer than $5 \mathrm{~s}$, and only bouts that included at least 10 handling times.

\section{Measuring trees and cones}

At the end of each feeding session we tagged each tree the cockatoos had fed in with plastic flagging tape bearing a unique label. For comparison we also tagged the $A$. verticillata nearest to each foraged tree that was not fed in during the session, and that held at least 20 cones. We recorded the girth of each tagged tree girth at $50 \mathrm{~cm}$ height, estimated its standing crop of unopened (seed bearing) cones, and recorded whether it had been fed in previously (as evidenced by darkened feeding litter on the ground). If there was more than one stem at $50 \mathrm{~cm}$ height, we measured each and calculated a single girth with the same total cross-sectional area, assuming cylindrical stems (total girth $=$ square root of sum of squares of separate girths). To estimate the standing crop of cones we counted the cones on 3-4 typical branches, and multiplied the average cones per branch by the number of branches.

From each tagged tree we had not sampled previously, we collected 20 unopened cones from the same age cohort the cockatoos had foraged on. We dried the cones in a drying oven at $40^{\circ} \mathrm{C}$ for 4 days, causing the valves to open. We then shook the cones to remove the seeds and removed any remaining seeds with forceps. We weighed the seeds from each tree and the cones from each tree on an electronic balance to the nearest milligram. Each tree's mean seed mass per cone was calculated by dividing total seed mass by the number of cones sampled. To measure mean seed size, we thoroughly mixed the seeds from one tree and 
weighed a sample of 50 . The mean number of seeds per cone was estimated for each tree as total seed mass per cone divided by mean seed size. Seed as a proportion of the total cone mass, or 'seed ratio', was calculated as seed mass per cone divided by seed mass plus empty cone mass. As an index of the relative density of cones on each tree, we used the residuals of cones per tree regressed against tree girth. For statistical analyses we log transformed tree girths and cone crops to improve normality. Statistical tests were twotailed unless otherwise noted, and were performed using the SYSTAT software package (Systat; SPSS, Chicago, IL, USA) (Wilkinson 1992).

\section{Categorising trees}

All trees tagged during the study were assigned to one of four categories: 'not foraged', 'preferred', 'accepted', or 'rejected'. Trees were categorised as 'not foraged' if they were tagged as the non-foraged comparison to a foraged tree. (We never saw a cockatoo feed in any of these trees.) Trees were categorised as 'rejected' if at least one cone was eaten from the tree, but in each bout the subject left to forage in a different tree after eating fewer than 10 cones (excluding cases in which the subject left the tree to join its mate). Trees were categorised as 'preferred' if (i) more than 10 cones were eaten from it during a bout, (ii) the tree was foraged in during more than one bout or had clearly been foraged in previously, and (iii) no cockatoos left it during a session to forage in another tree. Trees were categorised as 'accepted' if they were foraged in but were neither 'preferred' nor 'rejected'. The final sample included 63 'not foraged', 24 'preferred', 38 'accepted', and 11 'rejected' trees.

\section{Nutritional analysis}

To examine seed nutritional value, we pooled the seeds from oven-dried cones in each preference category ('preferred', 'accepted', and 'rejected'). We mixed the seeds and removed a subsample from each category for chemical analysis. We also analysed seeds from a random sample of $A$. verticillata trees. In a transect through the study area we sampled the first 10 female trees encountered, taking 20 first-year and 20 second-year cones from each tree and pooled the age classes for analysis. Finally, we sampled seeds from Allocasuarina muelleriana trees in a nearby stand where glossy blackcockatoos had fed on $A$. muelleriana the previous year (Pepper 1993). We collected 20 cones from each of 10 arbitrarily chosen large $A$. muelleriana trees and pooled them for analysis. All six samples of seeds (still in their samaras) were analysed for their content of water, protein $(=n \times 6.25)$, lipid, ash, crude fibre, and available carbohydrate $(=100 \%-[$ water + lipid + protein + ash + crude fibre]). Available energy was calculated from protein $\left(17 \mathrm{~kJ} \mathrm{~g}^{-1}\right)$, lipid $\left(37 \mathrm{~kJ} \mathrm{~g}^{-1}\right)$ and available carbohydrate $\left(17 \mathrm{~kJ} \mathrm{~g}^{-1}\right)$.

\section{RESULTS}

\section{Characteristics of trees and seed cones}

The characteristics of female drooping sheoaks are summarised in Table 1. Larger trees had more cones $\left(R^{2}=0.49, \quad P<0.001\right)$, larger seeds $\left(R^{2}=0.04\right.$, $P<0.05)$ and more seed mass per cone $\left(R^{2}=0.06\right.$, $P<0.01$ ), but girth was not correlated with number

Table 1. Measurements of female drooping sheoaks, by preference category (mean \pm standard error)

\begin{tabular}{|c|c|c|c|c|c|}
\hline \multicolumn{6}{|c|}{ (a) Tree characteristics } \\
\hline $\begin{array}{l}\text { Preference } \\
\text { category }\end{array}$ & $\begin{array}{l}\text { Girth } \\
(\mathrm{cm})\end{array}$ & $\begin{array}{l}\text { Seed-bearing } \\
\text { cones }\end{array}$ & $\begin{array}{l}\text { Stems at } \\
50 \mathrm{~cm} \mathrm{ht}\end{array}$ & & \\
\hline Preferred & $51.1 \pm 4.6$ & $402 \pm 92$ & $1.52 \pm 0.31$ & & \\
\hline Accepted & $34.1 \pm 3.3$ & $223 \pm 47$ & $1.08 \pm 0.05$ & & \\
\hline Rejected & $46.9 \pm 10.4$ & $314 \pm 108$ & $1.30 \pm 0.21$ & & \\
\hline Not foraged & $27.9 \pm 2.1$ & $211 \pm 36$ & $1.13 \pm 0.06$ & & \\
\hline \multicolumn{6}{|c|}{ (b) Seed and cone characteristics } \\
\hline $\begin{array}{l}\text { Preference } \\
\text { category }\end{array}$ & $\begin{array}{l}\text { Total cone } \\
\text { mass } \\
\text { (g) }\end{array}$ & $\begin{array}{c}\text { Empty } \\
\text { cone mass } \\
(\mathrm{g})\end{array}$ & $\begin{array}{l}\text { Seed mass } \\
\text { per cone } \\
(\mathrm{mg})\end{array}$ & $\begin{array}{l}\text { Seeds per } \\
\text { cone }\end{array}$ & $\begin{array}{c}\text { Mean } \\
\text { seed mass } \\
(\mathrm{mg})\end{array}$ \\
\hline Preferred & $5.9 \pm 0.3$ & $5.5 \pm 0.3$ & $384 \pm 25$ & $97.1 \pm 3.4$ & $3.9 \pm 0.2$ \\
\hline Accepted & $5.9 \pm 0.3$ & $5.5 \pm 0.3$ & $346 \pm 16$ & $93.0 \pm 2.2$ & $3.8 \pm 0.2$ \\
\hline Rejected & $6.3 \pm 0.4$ & $5.9 \pm 0.4$ & $368 \pm 29$ & $93.6 \pm 4.7$ & $3.9 \pm 0.2$ \\
\hline Not foraged & $5.6 \pm 0.2$ & $5.3 \pm 0.2$ & $317 \pm 11$ & $96.8 \pm 1.9$ & $3.3 \pm 0.1$ \\
\hline
\end{tabular}


of seeds per cone or ratio of seed-to-cone mass. Most of the variance in seed mass per cone was accounted for by the size of individual seeds, rather than the number of seeds per cone $\left(R^{2}=0.71\right.$ vs. 0.14 , $P<0.001$ for both). The ratio of seed-to-cone mass was correlated with total seed mass $\left(R^{2}=0.25, p<0.001\right)$ and one of its components, seed size $\left(R^{2}=0.18\right.$, $p<0.001$ ), but not with seeds per cone or empty cone mass.

Multi-stemmed trees apparently regrown from the base after fire comprised $15 \%$ of the total. They covered a smaller size range than single-stemmed trees (23-71 vs. 8-114 cm), and were larger in girth (mean of 43.4 vs. $34.0 \mathrm{~cm}, n=129$, $t$-test with separate variances, $t=3.94$, d.f. $=34.8, P<0.001)$. However, they did not differ significantly from single-stemmed trees in any measured characteristic of cones or seeds.

\section{Foraging behaviour}

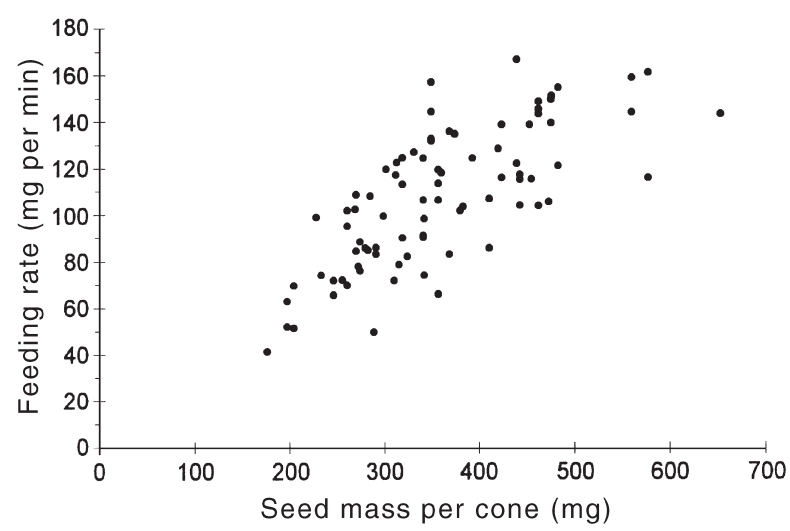

Fig. 1. Cockatoo feeding rate as a function of seed mass per cone.

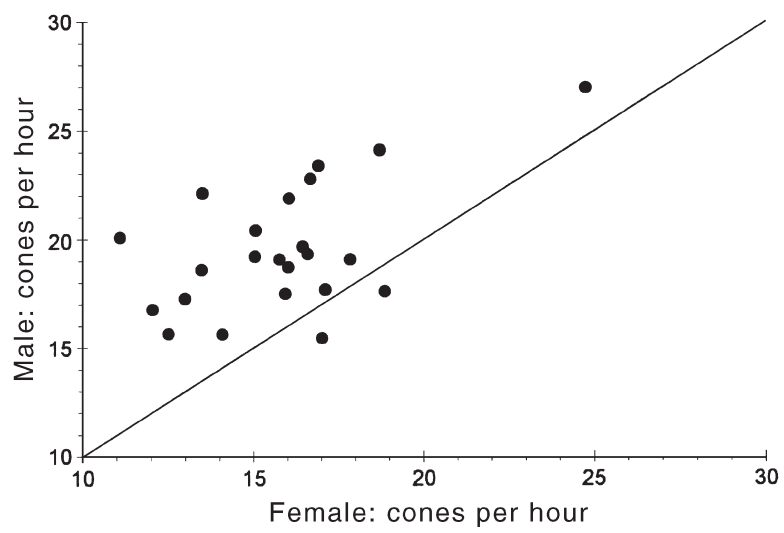

Fig. 2. Foraging efficiency of females versus males. Each point represents the feeding rates for a mated pair feeding in the same tree, including search and handling times. The diagonal line indicates equal foraging efficiency for female and male, with points above the line indicating faster foraging by the male.
The cockatoos fed only on closed seed cones. Foraging birds were rather sedentary; observation sessions were usually ended by the observer rather than the cockatoos, and subjects usually fed in only one tree during a session ( $85 \%$ of cockatoo sessions). Mated pairs usually fed in the same tree, while other individuals often fed nearby but rarely in the same tree. The cockatoos usually picked all cones within reach (mean of 6.25 cones) before walking or climbing a short distance within the tree.

The actual handling of cones occupied $94 \%$ of the cockatoos' foraging time. Averaging across the means from each bout, the cockatoos spent $12.7 \mathrm{~s}(\mathrm{SD}=8.4)$ searching for and travelling to each cone, and $194.9 \mathrm{~s}$ $(\mathrm{SD}=40.2)$ handling the cone and extracting seeds. The mean estimated feeding rate was $107.2 \mathrm{mg}$ of seed per min of foraging $(\mathrm{SD}=29.4)$. All but three $(99.8 \%)$ of the 1868 dropped cone ends we examined were distal ends, indicating the cone had been chewed starting at the proximal end. Most cone ends were small and appeared to contain no seeds, but $15.2 \%$ were larger and still contained seeds. Deformation and internal discoloration caused by insect larvae was evident in 7.7\% of the cone ends. Cone ends that were dropped before all seeds were extracted often showed evidence of insect infestation. Split and empty seed hulls were noticeable in the feeding litter beneath trees, but whole seeds were not.

\section{Factors affecting feeding rates}

To determine what qualities of drooping sheoaks affected search and handling times, we calculated average times for each foraging bout, then averaged the bouts in each tree. Linear regression showed search

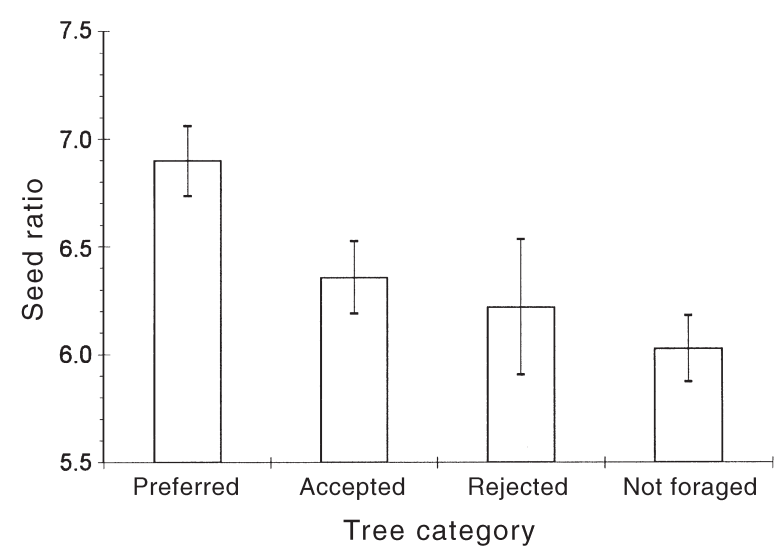

Fig. 3. Differences in seed ratio (seed mass/total cone mass) between tree preference categories. Bars show standard error of the mean. $n=126$, ANOvA, $P=0.013$; only 'preferred' and 'not foraged' differed significantly in a post-hoc pairwise test $(P=0.005)$. 
time to be correlated only with the tree's relative cone density $\left(R^{2}=-0.12, n=54\right.$ trees, $\left.P=0.01\right)$. Handling time per cone was correlated with cone size $\left(R^{2}=0.10\right.$, $n=44, P=0.032)$ and both of its components: empty cone mass $\left(R^{2}=0.10, P=0.033\right)$, and seed mass per cone $\left(R^{2}=0.10, P=0.037\right)$.

To examine overall food intake rates, we estimated the feeding rate ( $\mathrm{mg}$ of seed per min) during each foraging bout by multiplying cones chewed per minute by the tree's mean seed mass per cone. Feeding rate was not correlated with the characteristics of trees themselves except marginally for girth $\left(R^{2}=0.07, n=57\right.$ bouts, $P=0.047$ ). However, feeding rate was significantly correlated with all characteristics of seeds and cones. Seed mass per cone explained most of the variance in feeding rate $\left(R^{2}=0.55, n=57, P<0.001\right.$; Fig. 1).

There was a significant sex difference in feeding rates, with males consuming $19.3 \%$ more seed per minute of foraging than females $(n=83$ bouts, $t=2.87$, $P=0.005$ ). This was true of the nesting pair (male $28 \%$ faster) as well as individuals known not to be nesting (males 18\% faster on average). The difference was not attributable to the trees they fed in, as there were no sex differences across bouts in any tree measure ( $t$-test, $P>0.3$ for each variable). Instead, males foraged more efficiently in the same trees (Fig. 2). In paired comparisons of feeding bouts by mated pairs in the same tree at the same time, males were faster at searching by an average of $44 \%$ ( $5.1 \mathrm{~s}$ per cone; paired $t$-test, $n$ $=23, t=1.85$, one-tailed $P=0.039)$, and faster at handling cones by $23 \%$ ( $40.4 \mathrm{~s}$ per cone; paired $t$-test, $n=23, t=5.66$, one-tailed $P<0.001)$.

\section{Tree selection criteria}

Individual cockatoos often returned to trees they had fed in previously, and some trees were visited repeatedly for weeks until virtually stripped of cones. Of the 128 bouts observed, $63 \%$ were in trees with litter under them from a previous feeding bout, while the nearest non-foraged sheoak had litter under it in only $6 \%$ of bouts $\left(\chi^{2}=86.0\right.$, d.f. $\left.=1, P<0.001\right)$.

When not returning to a recently used tree, the cockatoos appeared to first choose a tree to sample, then quickly decide whether to accept or reject it. The number of cones eaten per bout had a bimodal distribution, with the cockatoos eating an average of only 1.8 cones from trees they rejected. This decision was anticipated by the rate at which they dropped partly eaten cones. Trees that at least one cockatoo had rejected had an average of $43 \%$ unfinished cones beneath them at the end of the session, compared with $14 \%$ under non-rejected trees (Mann-Whitney $U=184$, $P=0.004)$.

The cockatoos did not always sample the first tree they landed in, but sometimes moved to another tree before picking a cone. To investigate the criteria for this choice, we examined bouts in which neither the foraged tree nor the nearest non-foraged tree had any feeding litter beneath it from an earlier bout. Sampled trees differed from the nearest non-foraged tree only in having $14 \%$ larger seeds on average (paired $t$-test, $n=27, t=1.783$, one-tailed $P=0.043$ ).

To examine the decision to accept or reject a tree after sampling, we compared 26 bouts in 'rejected' trees with 90 bouts in 'accepted' and 'preferred' trees. The only significant difference was a $6 \%$ lower seed ratio in rejected trees $(t=2.17$, d.f. $=114$, one-tailed $P=0.016)$. This difference was more pronounced in a comparison of trees by preference category: 'preferred' trees had $11 \%$ higher seed ratios than 'rejected' trees $(n=33, t=2.07$, d.f. $=31$, one-tailed $P=0.024)$, and did not differ significantly in any other characteristic (Fig. 3). In contrast, seed size did not differ consistently among categories of foraged trees, despite being greater in foraged versus non-foraged trees (Table 1b; ANOVA among the four preference categories: $n=126, P=0.011$, only 'preferred' and 'not foraged' differed significantly in a post-hoc pairwise test $(P=0.026))$.

The presence of insect larvae in seed cones did not appear to affect tree selection. The proportion of cone ends showing signs of insect infestation per tree-session was unrelated to the proportion that were dropped unfinished $\left(R^{2}=0.01, P=0.42\right)$. Furthermore, trees rejected by at least one cockatoo during a session did not differ significantly from non-rejected trees in the proportion of cone ends showing insect damage (9.8 vs. $6.2 \%, t=0.75, P=0.46)$.

\section{Consequences of tree selection}

To measure the combined effects of both stages of tree selection (choice of trees to sample, and choice of sampled trees to remain in), we used pair-wise comparisons between foraged and nearest non-foraged trees for those bouts in which at least 10 cones were eaten. Foraged trees differed from their non-foraged neighbours in having $23 \%$ larger seeds (paired $t$-test, $n=73$, $t=4.44$, one-tailed $P<0.001$ ), $21 \%$ more seed per cone $(t=4.13$, one-tailed $P<0.001)$, and $14 \%$ higher seed ratio $(t=4.65$, one-tailed $P<0.001)$. Foraged trees were also much larger than their non-foraged neighbours, with a $70 \%$ larger girth and $233 \%$ more cones (one-tailed $P<0.0025$ for each). Multi-stemmed trees were not represented disproportionately among foraged versus non-foraged trees, or among preference categories (chi-squared test, $P>0.17$ ). To compare the profitability of foraged and non-foraged trees, we calculated an expected feeding rate for each tree from the linear regression of observed feeding rates against grams of seed per cone. Expected feeding rates were 
$13 \%$ higher for foraged trees than their non-foraged neighbours $(t=4.13$, one-tailed $P<0.001)$.

Foraged trees from the three preference categories also had more nutritious seeds than did randomly chosen trees. Seeds from foraged trees contained $25.5 \%$ more lipid, $9.4 \%$ more protein, $17 \%$ less crude fibre, and $12.7 \%$ more available energy per unit mass than seeds from randomly chosen trees. There were no consistent differences among the three preference categories (Table 2).

\section{DISCUSSION}

\section{Diet}

On Kangaroo Island, C. l. halmaturinus feeds primarily on Allocasuarina verticillata, but also rarely on $A$. muelleriana (Pepper 1993). During the current study the cockatoos had a choice between these two tree species in the same area. The fact that they fed only on $A$. verticillata seeds, even though they contained less energy and protein than those of $A$. muelleriana (Table 2), suggests that $A$. verticillata offered a substantially higher intake rate.

The tendency to maximise feeding rates may also explain why glossy black-cockatoos feed primarily on a single Allocasuarina species in each region (e.g. Allocasuarina torulosa in Queensland, A. littoralis in eastern New South Wales and eastern Victoria, and $A$. verticillata in inland New South Wales and South Australia; Forshaw 1981). Seeds from the same species appear to have similar characteristics in different areas. The seed mass of $3.57 \mathrm{mg}$ reported here for $A$. verticillata is comparable to the $3.82 \mathrm{mg}$ reported for the same species from Victoria (Withers 1978), and the protein content of $A$. littoralis was similar in Victoria (28.2\%, Withers 1978) and New South Wales (27.1\%, Clout 1989). In each area, the cockatoos may exploit only the species that provides the highest return rate, as has been shown in other specialist seed-eating birds that are nutritionally constrained by their handling efficiency (Benkman 1987).

All other black-cockatoos (Calyptorhynchus spp.) feed on insect larvae at least occasionally (Forshaw 1989), raising the question of whether insects are a significant source of nutrition for $C$. l. halmaturinus. Although $7.7 \%$ of chewed seed cones showed signs of insect larvae, the cockatoos' tendency to select trees with fewer infested cones and to drop infested cones at a higher rate suggests that they were not seeking larvae as a food source. This agrees with Clout's (1989) finding that C. l. lathami feeding on A. littoralis showed no obvious preference either for or against insectinfested seed cones. Despite these negative results, glossy black-cockatoos may sometimes feed on insect larvae. Allocasuarina trees host a variety of insects from several families (Andersen \& New 1987), which may vary substantially in their food value.

\section{Behavioural mechanisms of tree selection}

Tree selection appears to involve several stages of active choice. Past experience is probably important, as most bouts occurred in recently foraged trees even though most nearby trees did not show feeding signs. Returning to favoured trees may substantially reduce searching costs. It also creates a bias toward feeding in larger trees, which can be visited more times before their seed supply is exhausted. This is apparently why foraging bouts were concentrated in larger trees, even though the cockatoos did not prefer larger trees either in selecting a new tree to sample, or in accepting sampled trees.

The cockatoos appeared to use two rounds of selection to evaluate trees they had not fed in before. The first of these, choice of a tree to sample, was best predicted by seed size. This contrasts with the finding that glossy black-cockatoos in New South Wales preferentially sampled Allocasuarina trees with large cone crops

Table 2. Nutritional content of seeds, with percentages based on total dry mass. Each value represents one measurement of a pooled seed sample, representing a total of 141 trees

\begin{tabular}{|c|c|c|c|c|c|c|}
\hline & $\begin{array}{c}\text { Protein } \\
(\%)\end{array}$ & $\begin{array}{l}\text { Lipid } \\
(\%)\end{array}$ & $\begin{array}{c}\text { Available } \\
\text { carbohydrate } \\
(\%)\end{array}$ & $\begin{array}{l}\text { Crude } \\
\text { fibre } \\
(\%)\end{array}$ & $\begin{array}{l}\text { Ash } \\
(\%)\end{array}$ & $\begin{array}{c}\text { Available } \\
\text { energy } \\
\left(\mathrm{kJg}^{-1}\right)\end{array}$ \\
\hline \multicolumn{7}{|c|}{ Foraged drooping sheoak } \\
\hline Preferred & 24.6 & 22.4 & 23.2 & 25.2 & 4.8 & 16.4 \\
\hline Accepted & 23.2 & 23.1 & 23.8 & 24.7 & 5.1 & 16.6 \\
\hline Rejected & 24.2 & 21.8 & 23.7 & 25.6 & 4.8 & 16.2 \\
\hline \multicolumn{7}{|c|}{ Random drooping sheoak } \\
\hline First-year cones & 21.5 & 18.1 & 24.1 & 31.1 & 5.2 & 14.4 \\
\hline Second-year cones & 22.3 & 17.7 & 25.4 & 29.6 & 5.1 & 14.6 \\
\hline Random slaty sheoak & 31.6 & 18.8 & 20.6 & 21.4 & 7.7 & 15.8 \\
\hline
\end{tabular}


(Clout 1989). However, this earlier study did not measure seed size. Cone crop may also have been a more important criteria in the earlier study, in which only $23 \%$ of trees had $>200$ cones, than in the current study where most trees did (Table 1a). Although seed size was not the best predictor of feeding rate, it was highly correlated with the trait that was (seed mass per cone), and may be easier to assess. Seed size may also be a cue for nutritional factors such as lipid and protein content. It is not clear how the cockatoos could evaluate seed size before sampling cones but external cone morphology might provide visible cues.

The second stage in selecting new trees, the decision to stay or move on after sampling, was correlated mainly with seed ratio. Clout (1989) reported the same result for C. l. lathami feeding on A. littoralis. Although seed ratio was not an important determinant of feeding rate, it might influence net energy gain. Drooping sheoak cones are extremely tough and the ratio of seedto-cone mass may affect the amount of energy expended in extracting seeds and thus the rate of net energy gain.

\section{Feeding rates}

Our finding that cone size affected handling time per cone, but not seed intake rate, agreed with the results of Clout (1989) for feeding on A. muelleriana. Of the variables we measured, the best predictor of seed intake rate was total seed mass per cone.

\section{Sex differences in feeding rates}

Males foraged more efficiently than females and it seems unlikely that this was due to a size difference between the sexes. In a small sample of measured $C . l$. halmaturinus, males were slightly larger than females by some measures but smaller by others (Schodde et al. 1993). It also seems unlikely that males' slightly larger bills, ranging from 2 to $7 \%$ larger by various measures, could account for the observed $23 \%$ difference in handling efficiency. Instead, males probably need more food than females. This interpretation is consistent with the observations that males were faster at searching for cones as well as handling them, and that instead of reducing their foraging time to offset their greater efficiency, males spent more time foraging per day than did females (Pepper 1996). Males often regurgitate food for their mate, especially during the breeding season, and this would require increased food intake. However, this would not account for the equally high foraging efficiency of unpaired males. Another possible explanation for males' higher feeding efficiency and consumption rate is that they are more active than females during the breeding season and might therefore have higher metabolic costs (Pepper 1996).

\section{Food intake and nutritional requirements}

During the study period, non-nesting cockatoos foraged an average of $6.4 \mathrm{~h} \mathrm{day}^{-1}$ (Pepper 1996). Based on the average feeding rate of $107 \mathrm{mg}$ seed $\mathrm{min}^{-1}$, this

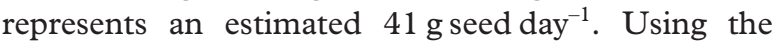
average nutritional values for trees that were either 'accepted' or 'preferred', this represents an estimated $626 \mathrm{~kJ}$ of available energy and $9.1 \mathrm{~g}$ of protein ingested per individual per day.

The nesting female and male foraged 2.8 and $6.1 \mathrm{~h}$ day $^{-1}$, respectively (Pepper 1996), yielding an estimated average of $29 \mathrm{~g} \mathrm{seed} \mathrm{day}^{-1}$ per bird. (Individual values could not be calculated because food is shared by regurgitation.) This translates into an estimated $438 \mathrm{~kJ}$ and $6.4 \mathrm{~g}$ of protein. Although we did not examine nests, all available evidence indicated that no nestling was present during the study.

These feeding rates appear to provide adequate energy and protein for non-nesting glossy blackcockatoos, based on the known requirements of similar sized birds (see Pepper 1996 for calculations). However, food is most limiting to birds that are feeding nestlings (Walsberg 1983). The breeding success of other black-cockatoos is sometimes limited by nutrition (Saunders \& Ingram 1987) and nutrition may be particularly limiting for glossy black-cockatoos as they are the only member of their genus with a clutch size that never exceeds a single egg (Forshaw 1989). In species for which handling efficiency is critical, food quality may be more important than quantity in determining reproductive success (e.g. Benkman 1990). Thus the quality of the food resources available during the nestling and early fledgling stages may be a limiting factor for glossy black-cockatoo reproduction.

\section{Feeding profitability and habitat selection}

As predicted, based on the earlier study by Clout (1989), the cockatoos did tend to select the more profitable trees to feed in. However, feeding rate was not the sole predictor of tree choice, because favoured trees also had more nutritious seeds. Therefore, the estimated rate of energy intake proved to be the best predictor of tree choice. The combined effects of a $13 \%$ faster intake rate and a $13 \%$ higher energy content produced a $28 \%$ increase in the rate of energy intake as a result of tree selection. The cockatoos' preference for cones with less hard woody material also suggests they may optimise their net rate of energy gain, after accounting for the energy expended in shredding cones.

The impact of fire on habitat selection is a significant conservation issue for glossy black-cockatoos on 
Kangaroo Island because $A$. verticillata woodland is quite vulnerable to fire (Pepper 1997). The narrow size distribution of multistemmed trees was consistent with an origin from basal re-sprouting after a fire. Past exposure to fire did not appear to permanently change these trees' foraging profitability. Multi-stemmed trees did not differ significantly from single-stemmed trees in any measured cone or seed characteristic, and the cockatoos did not avoid them while feeding.

Potential foraging profitability appears to affect not only the cockatoos' preferences for individual trees but also their habitat choice on a much larger scale. The characteristic of drooping sheoaks that best predicted feeding profitability among individual trees (seed mass per cone) was also the best predictor of habitat use on a regional scale (Pepper 1997). This may be due to the fact that glossy black-cockatoos spend nearly all their foraging time actually handling food as opposed to searching for it (Clout 1989; Pepper 1996). As a result, the factor limiting their energy budgets is usually handling efficiency rather than the quantity of food available. This unusual circumstance may influence various aspects of the species' behaviour and ecology, including habitat choice. A similar pattern has been described in North American crossbills (Loxia spp.), which also specialise on closed seed cones and spend most of their foraging time extracting seeds. Crossbills choose individual trees that maximise their feeding rates, and their abundance on both local and continentwide scales is correlated with patterns of food profitability (Benkman 1987).

The link between local food profitability and the distribution of C. l. halmaturinus suggests that this endangered subspecies' range may be limited not only by the availability of drooping sheoak woodland, but also by its foraging profitability. If so, this has important implications for conservation and management. Given the similar feeding preferences among individual trees shown by C. l. lathami feeding on Allocasuarina littoralis in New South Wales (Clout 1989), the same factor may influence the distribution and conservation status of other populations of glossy black-cockatoos as well.

\section{ACKNOWLEDGEMENTS}

This research was supported by the University of Michigan's Department of Biology, Museum of Zoology, and Rackham Graduate School, and by Richard D. Alexander and John C. Mitani. Additional support was provided by the 1991 Reunion of the Zoology Graduate Students of the University of Michigan, the Chicago Zoological Society, The Explorers Club, Sigma Xi, and the T. C. Schneirla Research Fund. Thanks also to Dr Ken Sanderson for sponsoring J.W.P.'s studies in Australia, the South Australian National Parks and Wildlife Service for permission to work in the parks, and the Prime and
Stanton families for permission to work on their properties. Gillian Haines helped process and weigh samples, Lynn Dohle and the Department of Primary Industries provided the drying oven, Ian Sarson and the Parndana Area School provided the electronic balance, and Heather Lindsay and the State Chemistry Laboratories of South Australia provided the nutritional analyses of seeds. The manuscript was improved by the comments of Richard D. Alexander, Gabriel Crowley, Stephen Garnett, John C. Mitani, Robert B. Payne, and Barbara B. Smuts.

\section{REFERENCES}

Andersen A. N. \& New T. R. (1987) Insect inhabitants of fruits of Leptospermum, Eucalyptus, and Casuarina in south-eastern Australia. Aust. F. Zool. 35, 327-36.

Anon. (1976) Reader's Digest Complete Book of Australian Birds. Reader's Digest Services, Sydney.

Baxter C. (1989) An Annotated List of the Birds of Kangaroo Island. The National Parks and Wildlife Service and Angel Press, Kingscote, South Australia.

Benkman C. W. (1987) Food profitability and the foraging ecology of crossbills. Ecol. Monogr. 57, 251-67.

Benkman C. W. (1990) Intake rates and the timing of crossbill reproduction. Auk 107, 376-86.

Blakers M., Davies S. J. F. \& Reilly P. N. (1984) The Atlas of Australian Birds. Royal Australasian Ornithologists Union, Melbourne University Press, Melbourne.

Cleland J. B. \& Sims E. B. (1968) Food of the Glossy Black Cockatoo. South Aust. Ornithol. 25, 47-52.

Clout M. N. (1989) Foraging behaviour of Glossy Black Cockatoos. Aust. Wildl. Res. 16, 467-73.

Forshaw J. M. (1981) Australian Parrots, 2nd edn. Lansdowne, Melbourne.

Forshaw J. M. (1989) Parrots of the World, 3rd edn. Lansdowne, Melbourne.

Garnett S. (ed.) (1992) Threatened and Extinct Birds of Australia. Australian National Parks and Wildlife Service and Royal Australasian Ornithologists Union, Canberra.

Joseph L. (1982) The glossy black-cockatoo on Kangaroo Island. Ети 82, 46-9.

Pepper J. W. (1993) A new food source for the glossy black cockatoo. South Aust. Ornithol. 31, 144-5.

Pepper J. W. (1996) The behavioral ecology of the glossy blackcockatoo Calyptorhynchus lathami halmaturinus. PhD Thesis, The University of Michigan, Ann Arbor.

Pepper J. W. (1997) A survey of the South Australian glossy blackcockatoo (Calyptorhynchus lathami halmaturinus) and its habitat. Wildl. Res. 24, 209-23.

Saunders D. A., Ingram J. A. (1987) Factors affecting survival of breeding populations of Carnaby's cockatoo (Calyptorhynchus funereus latirostris) in remnants of native vegetation. In: Nature Conservation: the Role of Remnants of Native Vegetation (eds Saunders D. A. et al.) pp. 249-58. Surrey Beatty \& Sons, Chipping Norton, New South Wales.

Schodde R., Mason I. J. \& Wood J. T. (1993) Geographic differentiation in the glossy black-cockatoo, Calyptorhynchus lathami (Temminck), and its history. Еmu 93, 156-66.

Walsberg G. E. (1983) Avian ecological energetics. In: Avian Biology, vol. VII (eds Farner D. S., King J. R. \& Parkes K. C.) pp. 161-220. Academic Press, New York.

Wilkinson L. (1992) SYSTAT for Windows: Statistics, Version 5. Systat, Evanston, IL. 
Wilson K. L., Johnson L. A. S. (1989) Casuarinaceae. In: Flora of Australia, vol. 3, Hamamelidales to Casuarinales (eds Robertson R. et al.) pp. 100-74. Australian Government Publishing Service, Canberra.
Withers J. R. (1978) Studies on the status of unburnt Eucalyptus woodland at Ocean Grove, Victoria. II. The differential seedling establishment of Eucalyptus ovata Labill. \& Casuarina littoralis Salisb. Aust. F. Bot. 26, 465-83. 